\title{
Developing advanced hospital pharmacy practice experiences in a Bachelor of Pharmacy programme in Jordan: A novel training programme and evaluation of student perceptions
}

Yazan S. Batarseh 1, Michael J. Rouse 2, Rowan AlEjielat 1, Anas Khaleel 1, Mohammad Aluwidi 1, Diana Ayyad 3, \& Yara Haddadin 3

${ }^{1}$ Department of Pharmacy and Biomedical Sciences, Faculty of Pharmacy and Medical Sciences, University of Petra, Amman, Jordan

2 Accreditation Council for Pharmacy Education, USA

${ }^{3}$ Al-Basheer Hospital, Amman, Jordan

\section{Keywords}

Al-Basheer Hospital

Clinical Pharmacy

Hospital Training

University of Petra

\section{Correspondence}

Yazan S. Batarseh

Department of Pharmacy and

Biomedical Sciences,

Faculty of Pharmacy and Medical

Sciences, University of Petra,

Amman,

Jordan

yazan.batarseh@uop.edu.jo

\begin{abstract}
Objective: To describe, introduce, and assess student perceptions of a structured clinical training programme for pharmacy students that meets the expectations of advanced pharmacy practice experiences of Doctor of Pharmacy (Pharm.D.) programmes accredited by the Accreditation Council for Pharmacy Education. Methods: A clinical training programme was held from July to September 2019. Training included hands-on hospital rotations focusing on essential pillars of pharmaceutical care including ensuring proper medical indication, effectiveness, safety, and patient adherence (total of 160 hours). The study population included 35 senior pharmacy students from the University of Petra. Results: Qualitative answers from students showed positive responses associated with the programme's pre-training orientation, clinical training, preceptors involved, and student's clinical knowledge and skills. Conclusion: The piloted introduction of a structured clinical training programme for pharmacy students was successful. Students reported positive evaluations and perceptions of clinical training sites and staff as well as their clinical and practical skills. The main challenge students encountered was transportation to the practice site.
\end{abstract}

\section{Introduction}

Over the last decade, pharmacy education and practice in Jordan has started to expand (Kheir et al., 2008) to include increasing numbers of pharmacy graduates, with two major programmes offered by governmental and private institutions (Al-Wazaify et al., 2006). The demand for pharmacists has increased with the growing number of pharmacies, now reaching 2500 community pharmacies located in different regions of Jordan (Nazer \& Tuffaha, 2017). An introductory pharmacy practice programme offered as a bachelor of science (B.Sc.) in pharmacy is currently available at 18 schools of pharmacy; the B.Sc. programme requires the completion of 160 credit hours and 1440 internship hours as part of the Jordan Pharmaceutical Association pre-enrolment requirement (Al-Wazaify et al., 2006). Internships can be fulfilled in hospital and community pharmacies. On the other hand, the Doctor of Pharmacy (Pharm.D.) programme, offered by only two governmental schools, provides an advanced pharmacy training opportunity or as it is often called Advanced Pharmacy Practice Experiences (APPEs); this programme includes 219 credit hours. The final sixth year of the programme is considered an experiential year, in which students are exposed to 14 weeks of community and hospital pharmacy training, followed later by five 
connected six-week hospital rotation cycles in different medical departments (Al-Wazaify et al., 2006). Although there is a clear distinction in the curriculums of the two offered programmes, this distinction is not clearly observed in actual pharmacy practice. In Jordan, pharmacists with both Pharm.D. and B.Sc. in pharmacy degrees are considered pharmaceutical care providers and are allowed to counsel, dispense medication, and provide pharmacotherapy management to patients in both community and hospital settings (Ababneh et al., 2019; Basheti et al., 2019; Mukattash et al., 2018; Tahaineh et al., 2019). Academic pharmacy institutions in the United States of America (USA) were among the first to transition from traditional B.Sc. in pharmacy into more advanced Pharm.D. degrees (Supapaan et al., 2019). Moreover, studies conducted in the USA show that although pharmacists with a Pharm.D. degree have a clear advantage in a hospital setting, in which they contribute to patient care in medical floors and critical care units (Anderson, \& Marrs, 2018; Basri et al., 2018; Moore, \& Kenworthy, 2017), B.Sc. holders are also required to have independent and critical roles in inpatient and outpatients pharmacies (Stewart, Thomas, \& Tutag-Lehr, 2018). Pharm.D. programmes in Jordan offer structured advanced pharmacy hospital training. However, contrary to community pharmacy training, hospital training in introductory (B.Sc.) programmes do not share the same organisational structure with varying exposures to the hospital environment. A lack of clinical training focus on patient oriented pharmaceutical care, where students get to interact with the health care team and patients has been observed in hospital settings for B.Sc. students (AbuBlan et al., 2019). The Accreditation Council For Pharmacy Education (ACPE) recognises hospital training as a required area of APPE (ACPE, 2015). ACPE also provides insights on the optimal settings for APPEs to be conducted efficiently. ACPE accreditation standards focus on the following:

1. Patient care emphasis; APPEs applied in a hospital setting should involve patients with both acute and chronic conditions. Additionally, providing preventative care and wellness promotion in a hospital setting

2. Diverse populations; APPEs should expose students to special populations of patients including geriatrics, paediatrics, women's health, and socioeconomic aspects

3. Inter-professional experiences; APPEs should expose students to different members of the health care team in a hospital setting including nurses, physicians, pharmacists, and other healthcare professionals
4. APPE duration; each APPE should consist of a minimum of 160 hours of focused direct patient care

5. Timing; APPEs should follow the students passing prior Introductory Pharmacy Practice Experiences (IPPEs) in order to obtain a proper background to maximise the benefit of APPEs

[ACPE, 2015]

The University of Petra (UOP) pharmacy degree programme is certified by ACPE using the Certification Quality Criteria (QC) (University of Petra, n.d.). The Certification QC are applied globally in the context of different countries and degree programmes. The $Q C$ are, by design, not as specific and detailed as the ACPE accreditation standards; which were designed to be applicable to only Pharm.D. programmes in the USA. It was, however, UOP's objective to meet the expectations of the Pharm.D. accreditation standards for APPEs when designing its practice experiences for this pilot.

The aim of this study is to describe this new programme designed at UOP because the B.Sc. of Pharmacy curricula do not focus on this type of clinical training in Jordan. Moreover, the authors also aimed to measure student perceptions of this pilot programme to investigate its acceptability and expandability.

\section{Methods}

A pilot training programme was designed by the UOP and implemented in cooperation with Al-Basheer Hospital, one of the largest governmental hospitals in Jordan.

This training pilot started with a three hour session at the inpatient pharmacy in which students were introduced to the standard and daily inpatient pharmacy operations. This was followed by a concentrated and intensive clinical training in internal medicines, paediatrics, orthopaedics, and critical care departments.

The study was supervised by a clinical pharmacy faculty member of UO, who served as an internal preceptor, in addition to a team of external preceptors, who also operated under direct supervision of the pharmacy department director at Al-Basheer Hospital. Both internal and external preceptors accompanied the students during the entire pilot trial facilitating different aspects of clinical training. This study started in July and finished in September 2019. Students participated in the clinical training three days a week. They spent eight hours a day for the first two days in medical wards and four hours a day for the third day participating in oral case discussions 
for a period of eight weeks (totalling 160 hours). The study population included 35 students from the UOP pharmacy school who were in their fifth year. The students had to have completed the Clinical Pharmacy I module to be included in the study.

\section{Pre-clinical training and orientation}

Students attended two orientation sessions; one extensive orientation at the campus at the Faculty of Pharmacy and Medical Sciences (FPMS) UOP, and the other at Al-Basheer Hospital, before starting the study. The orientation at the UOP campus aimed to prepare students through a detailed workshop on case preparation, medical file components, inter-professional communication skills, and patient interview skills. The orientation at Al-Basheer Hospital included ensuring patient privacy, introduction to hospital departments, and general safety precautions. All students were required to take essential vaccinations if not already taken, and to provide proof of vaccinations as per hospital policy.

\section{Inpatient pharmacy training session}

This was a three hour session at the inpatient pharmacy. Students were introduced to prescription filling, common medication errors, sterile medication preparation, and other things related to the operation system in the hospital.

\section{Clinical training}

The clinical training had three core stages described below:

\section{Stage-1: Case selection and patient profiling}

Students were allocated to several nursing stations and were allowed to divide into teams of three to four and then choose a medical case taking into consideration the medical condition, medications, and availability of laboratory information. Students then consulted with different resources to create their patient profile. These resources included talking with the attending physician and conducting patient interviews if necessary, collecting laboratory test results and physician notes found physically in patients' medical files and virtually on the Hakeem computerised patient filing system. Students also participated in physician medical rounds and medication related discussions.

\section{Stage-2 Identifying treatment related problems}

After selecting medical cases, patient profiling, and data collection, students started to identify treatment related problems focusing on proper medical indication, effectiveness, safety, and patient adherence. Problems in medication effectiveness and safety were commonly encountered.

One of the common problems was related to the dosing of medications, especially antibiotics. Other common problems were over prescribing of antibiotics without indication or selecting the strongest newest generation from the list of medications that are active against the bacteria of interest, which can contribute to resistance. Moreover, medication monitoring frequency for drugs such as for warfarin, digoxin and over prescription of proton pump inhibitors were also noted as medication related problems.

\section{Stage-3 Formulating pharmaceutical care plans}

Students were asked to put together a pharmaceutical care plan taking into consideration each medical condition, therapeutic targets, treatment related problems, evidence based detailed non-pharmacological and pharmacological recommendations, and monitoring/ follow-up parameters.

Implementation of students' pharmaceutical care plans took place through arrangements with preceptors; clinical pharmacists would be notified, and proper physician interventions would take place in management changing treatment related problems.

\section{Pharmacotherapy resources used by students}

Students utilised several resources and databases to accurately identify treatment related problems, create detailed pharmaceutical care plans, and prepare for their evaluation. Resources included treatment guidelines such as the American College of Cardiology, American Heart Association, and American Diabetes Association Practice Guidelines. Furthermore, drug information handbooks were used to retrieve accurate and updated information about dosage regimens and medication monitoring parameters such as Lexi-Comp Drug Information Handbook (Lexi-Drugs, n.d.). Drug-drug interaction databases were consulted to identify effectiveness and safety related drug-drug interactions and interventions possibilities; an example of a database used is the one provided by www.drugs.com (Drugs.com | Find Drugs \& Conditions, 2021). 


\section{Student Evaluation}

Students were evaluated on a daily basis in the form of daily discussions, assignments, and homework. In addition, students had a weekly formal evaluation; each group met the internal preceptor to present their case and discuss medical knowledge, treatment related problems, and specific recommendations included in their pharmaceutical care plans. Accordingly, their weekly assessments combined with their final exam in open-book format were used to give students their final evaluations and grades.

\section{Measurement instruments}

A questionnaire was designed to assess the students' satisfaction of the different aspects of the training programme. The questionnaire contained five sections. The first section consisted of students' evaluation of the pre-training orientation part of the programme; The second section consisted of students' evaluation of the clinical training part; the third section consisted of students' assessment of the training site; the fourth section consisted of students' evaluation of their preceptor; the fifth section consisted of student's evaluations of their own skills and knowledge after taking part in this training. The questionnaire parts are represented in Tables I-V below. The answers of the questionnaire were reported on a 5-point Likert scale (strongly disagree, disagree, neutral, agree, strongly agree). Some answers were also reported as (very low, low, neutral, high, very high). The answers were then merged into three categories (disagree, neutral, agree) or (low, neutral, high).

The questionnaire was developed by the clinical faculty at the time of the study, questions were put through brainstorming and based on the expected student experiences during the training. The questionnaire was distributed electronically (using the google form free service) after the training was finished (in September 2019) to the students who participated in the training. Data was collected and analysed using MS Excel software

The authors also collected qualitative data in the form of student testimonials, describing their experiences in their own words.

\section{Results}

A total of 25 students out of 35 who participated in training completed the questionnaire. In general, the majority of students were highly satisfied with their experience. Details of answers on each section of the questionnaire are presented below. Appendix 1 includes student testimonials translated from Arabic.

\section{1: Pre-training orientation assessment}

As illustrated in Table I, A total of $84.6 \%$ of students understood the objectives of the clinical training experience prior to beginning in hospital rotations. Furthermore, students agreed that information regarding patient privacy, health and safety were given clearly during induction courses. Also, $92.0 \%$ of students felt that orientation conducted at UOP adequately prepared them for the clinical training and overall learning experience (Table I).

Table I: Pre-training orientation assessment of participants $(n=25)$

\begin{tabular}{ll}
\hline Questions & $\mathbf{N}(\%)$ \\
\hline $\begin{array}{l}\text { I understood the objectives of this clinical training experience } \\
\text { prior to beginning } \\
\text { Disagree }\end{array}$ & $1(3.8)$ \\
Neutral & $3(11.6)$ \\
Agree & $22(84.6)$
\end{tabular}

Information regarding patient privacy, health and safety were given clearly during induction course

$\begin{array}{ll}\text { Disagree } & 1(4.0) \\ \text { Neutral } & 2(8.0) \\ \text { Agree } & 22(88.0)\end{array}$

I feel that orientation conducted in UOP adequately prepared me for the clinical training

$\begin{array}{ll}\text { Disagree } & 1(4.0) \\ \text { Neutral } & 1(4.0) \\ \text { Agree } & 23(92.0)\end{array}$

\section{2: Clinical training programme assessment}

As illustrated in Table II, significant number of students, felt that the clinical training programme objectives were clear and agreed that knowledge resources and databases needed for case preparation were available to them. The majority of students felt that they were given opportunities to observe the clinical pharmacist role in essential services at the hospital. Moreover, $84.0 \%$ of students agreed that they were given opportunities to observe the clinical pharmacist while interacting with physicians and 
patients. Additionally, students felt they were given a chance to communicate with patients, staff, and other healthcare professionals. Most students also agreed that they were given the opportunity to participate in medical rounds and that their formal weekly case evaluation was useful in increasing their clinical pharmacy skills. Students agreed that the number of hours required for the learning experience was appropriate. The majority of students agreed to recommend this clinical training to their student peers (Table II).

\section{Table II: Clinical training assessment of participants $(\mathbf{n}=$} 25)

\begin{tabular}{|c|c|}
\hline Questions & $N(\%)$ \\
\hline \multicolumn{2}{|c|}{ Were the course objectives clear? } \\
\hline Disagree & $2(8.0)$ \\
\hline Neutral & $2(8.0)$ \\
\hline Agree & $21(84.0)$ \\
\hline \multicolumn{2}{|c|}{$\begin{array}{l}\text { Knowledge resources and databases needed for case } \\
\text { preparation were available to me }\end{array}$} \\
\hline Disagree & $1(4.0)$ \\
\hline Neutral & $1(4.0)$ \\
\hline Agree & $23(92.0)$ \\
\hline \multicolumn{2}{|c|}{$\begin{array}{l}\text { I was given opportunities to observe the clinical pharmacist role } \\
\text { in essential services in a hospital setting }\end{array}$} \\
\hline Disagree & $1(4.0)$ \\
\hline Neutral & $2(8.0)$ \\
\hline Agree & $22(88.0)$ \\
\hline
\end{tabular}

I was given opportunities to observe the clinical pharmacist interact with physicians and patients

$\begin{array}{ll}\text { Disagree } & 1(4.0) \\ \text { Neutral } & 3(12.0) \\ \text { Agree } & 21(84.0)\end{array}$

I was given opportunities to communicate with patients, staff, and other healthcare professionals

$\begin{array}{ll}\text { Disagree } & 1(4.0) \\ \text { Neutral } & 2(8.0) \\ \text { Agree } & 22(88.0)\end{array}$

I was given opportunities to participate in medical rounds

$\begin{array}{ll}\text { Disagree } & 1(4.0) \\ \text { Neutral } & 2(8.0) \\ \text { Agree } & 22(88.0)\end{array}$

Formal weekly case evaluation was useful in increasing my clinical pharmacy skills

$\begin{array}{ll}\text { Disagree } & 1(4.0) \\ \text { Neutral } & 2(8.0) \\ \text { Agree } & 22(88.0)\end{array}$

I feel that the number of hours required for the learning experience was appropriate

$\begin{array}{ll}\text { Disagree } & 1(4.0) \\ \text { Neutral } & 1(4.0) \\ \text { Agree } & 23(92.0)\end{array}$

I recommend this clinical training for other students

Disagree $1(4.0)$

Neutral $1(4.0)$

Agree $23(92.0)$

\section{3: Hospital site assessment}

As shown in Table III, a significant number of students felt that orientation conducted in Al-Basheer Hospital adequately prepared them for the clinical training. A majority of students thought that hospital resources needed for case preparation were available to them. Meanwhile, $92.0 \%$ of students agreed that areas designated for group discussions and meetings were made available when requested. In contrast, students were dissatisfied with the transportation; when students were asked if transportation methods were satisfactory; $40.0 \%$ disagreed, $24.0 \%$ were neutral and $36.0 \%$ agreed. When students were asked how they would rate the skills of the medical staff, a large number of students rated the skills of the staff as high (Table III).

\section{4: Preceptor assessment}

As represented in Table IV, most students felt that the preceptor's assessment of their performances were fair. Also, students found that the daily case evaluation by the preceptor was useful for their overall understanding of the case. Students felt that the preceptor was available to them and able to answer their questions. A majority agreed that the preceptor was effective in communicating

Table III: Hospital site assessment of participants $(n=25)$

\begin{tabular}{|c|c|c|}
\hline Questions & $N(\%)$ & \\
\hline $\begin{array}{l}\text { I feel th } \\
\text { adequatel }\end{array}$ & $\begin{array}{l}\text { ducted in Al-Basheer } \\
\text { e clinical training. }\end{array}$ & Hospital \\
\hline Disagree & $1(4.0)$ & \\
\hline Neutral & $3(12.0)$ & \\
\hline Agree & $21(84.0)$ & \\
\hline
\end{tabular}

Hospital resources needed for case preparation were available to me

$\begin{array}{ll}\text { Disagree } & 1(4.0) \\ \text { Neutral } & 2(8.0) \\ \text { Agree } & 22(88.0)\end{array}$

Areas designated for group discussions and meetings were made available when requested

$\begin{array}{ll}\text { Disagree } & 1(4.0) \\ \text { Neutral } & 1(4.0) \\ \text { Agree } & 23(92.0)\end{array}$

The transportation methods were satisfactory.

$\begin{array}{ll}\text { Disagree } & 10(40.0) \\ \text { Neutral } & 6(24.0) \\ \text { Agree } & 9(36.0)\end{array}$

How would you rate the skills of the medical staff?

$\begin{array}{ll}\text { Low } & 0(0.0) \\ \text { Neutral } & 2(8.0) \\ \text { High } & 23(92.0)\end{array}$


the content of the course, had high knowledge and competence, and able to determine goals and priorities (Table IV).

\section{5: Students' assessment of their knowledge and skills}

As demonstrated in Table V, students agreed that they had a deeper understanding of the concept of pharmaceutical care after this clinical training. Also, they agreed they were able to apply the information they learned in the theoretical courses to this clinical learning experience. Students (92.0\%) rated their pharmacotherapy planning skills after finishing the training and their skills in presenting clinical cases as high. Furthermore, students suggested that they recognised the desired outcomes of drug therapy of the selected diseases. Also, they appreciated the value of collecting and interpreting information from practice treatment guidelines. More-

Table IV: Participants preceptor assessment $(n=25)$

Questions
$\begin{array}{ll}\text { I feel that the preceptor's assessment of } \\ \text { the objectives was fair } \\ \text { Disagree } \\ \text { Neutral } & 1(4.0) \\ \text { Agree } & 1(4.0) \\ & 23(92.0)\end{array}$

Daily case evaluation by the preceptor was useful for my overall understanding of the case

$\begin{array}{ll}\text { Disagree } & 1(4.0) \\ \text { Neutral } & 2(8.0) \\ \text { Agree } & 22(88.0)\end{array}$

I feel that the preceptor was available to me and able to answer my questions

$\begin{array}{ll}\text { Disagree } & 1(4.0) \\ \text { Neutral } & 2(8.0) \\ \text { Agree } & 22(88.0)\end{array}$

The preceptor was effective in communicating the content of the course?

$\begin{array}{ll}\text { Disagree } & 0(0.0) \\ \text { Neutral } & 0(0.0) \\ \text { Agree } & 25(100)\end{array}$

How would you rate the preceptor knowledge and competence?

$\begin{array}{ll}\text { Low } & 0(0.0) \\ \text { Neutral } & 1(4.0) \\ \text { High } & 24(96.0)\end{array}$

How would you rate the preceptor ability to determine goals and priorities?

$\begin{array}{ll}\text { Low } & 0(0.0) \\ \text { Neutral } & 0(0.0) \\ \text { High } & 25(100)\end{array}$

over, students felt that their knowledge or skills have improved by taking the course (Table V).

\section{Discussion}

Pharmacy practice has been changing for over three decades in the developed world. With an additional focus on pharmaceutical care and patient care (Benrimoj, \& Roberts, 2005; Christensen \& Farris, 2006; Fang et al., 2013; Hogue et al., 2006; Koga, \& Nishimura, 2017; Nagai, 2003; Pittenger et al., 2016; Saavedra-Mitjans et al., 2018;

Table V: Student's knowledge and skills assessment (n = 25)

\begin{tabular}{l}
\hline Questions \\
$\begin{array}{ll}\mathbf{N}(\%) \\
\text { I have a deeper understanding of the concept of } \\
\text { pharmaceutical care after completing this clinical training } \\
\text { Disagree } & 1(4.0) \\
\text { Neutral } & 1(4.0) \\
\text { Agree } & 23(92.0)\end{array}$
\end{tabular}

I was able to apply the information I learned in the theoretical courses to this clinical learning experience

$\begin{array}{ll}\text { Disagree } & 1(4.0) \\ \text { Neutral } & 0(0.0) \\ \text { Agree } & 24(96.0)\end{array}$

How would you rate your pharmacotherapy planning skills after finishing this course?

$\begin{array}{ll}\text { Low } & 0(0.0) \\ \text { Neutral } & 2(8.0) \\ \text { High } & 23(92.0)\end{array}$

How would you rate your skills in presenting clinical cases?

Disagree $0(0.0)$

Neutral $2(8.0)$

Agree $23(92.0)$

Do you recognize the desired outcomes of drug therapy of the selected diseases?

$\begin{array}{ll}\text { Disagree } & 1(4.0) \\ \text { Neutral } & 2(8.0) \\ \text { Agree } & 22(88.0)\end{array}$

How would you rate your skills in collecting and interpreting information from practice treatment guidelines after this clinical training?

$\begin{array}{ll}\text { Low } & 0(0.0) \\ \text { Neutral } & 3(12.0) \\ \text { High } & 22(88.0)\end{array}$

Do you feel that your knowledge or skills have improved by taking the course?

$\begin{array}{ll}\text { Disagree } & 2(8.0) \\ \text { Neutral } & 2(8.0) \\ \text { Agree } & 21(84.0)\end{array}$


Westerlund, \& Bjork, 2006). In Jordan, there have been changes in curriculums, with the addition of the Pharm.D. degree in 2000 (Al-Wazaify et al., 2006). However, practice hasn't changed much (Al-azzam et al., 2013). Pharmaceutical care has been included in teaching curriculums without highly bridging theory to practice. Although the Pharm.D. programme has been running in Jordan, there is a lack of appreciation for the newer clinical role of pharmacists by many health care individuals including physicians (Al-azzam et al., 2013).

The degree programme of FPMS at the UOP is certified by the ACPE. With the accreditation bodies such as the ACPE having a large role in improving the education process, and with the shift towards a more patient centred care, a need to improve clinical pharmacy training programmes has emerged in pharmacy academia (ACPE, 2015). In order to meet this need, we have designed and implemented a clinical pharmacy hospital training programme in UOP, FPMS. It offers a B.Sc. degree in Pharmacy in Jordan. To the authors knowledge, this is the first clinical pharmacy hospital training in a B.Sc. degree programme that is designed to meet the ACPE Certification Quality Criteria for pharmacy practice experiences as an APPE.

Initially, this programme was designed to meet the requirements of the ACPE Pharmacy Accreditation Standards, as part of wide changes to the curriculum at the Faculty of Pharmacy, UOP, but as the authors see it, this is a step to move the pharmacy profession further in developing countries like Jordan through improving pharmacy education. The proportion of courses geared towards pharmaceutical care in pharmacy programs in Jordan has increased from $20.0 \%$ in 2008 to $50.0 \%$ in 2016, but this was mainly implemented in the Jordan University of Science and Technology and the University of Jordan (the only two schools that offer Pharm.D. programmes) (Alefan, \& Alsmadi, 2017). Before the introduction of Pharm.D. programmes, there have been sporadic non-standardised patient focused, hospital-based training, mainly in the governmental universities for the B.Sc. degree of pharmacy, which was gradually minimised and refocused to Pharm.D. students. Our clinical training programme aims to teach students how to apply the principles of pharmaceutical care in a hospital setting. It includes many of the pillars that define pharmaceutical care, with a high focus on identifying potential or actual treatment related problems in the major areas of drug indication, effectiveness, safety and patient adherence.

The programme discussed was also designed to include inter-professional interaction, patient interviewing and assessment skills. The students were also taught to consult with multiple evidence-based medicine and drug information databases. The overall impression and assessment of this programme by the students was highly positive. Also, from student's testimonials it was evident that this programme helped students understand the essence of pharmaceutical care practice and recognise their professional role.

Another strength of this programme is the training site. The programme was conducted in a major public hospital that serves a diverse patient population including geriatric, paediatric, surgery, critical care, and emergency care. In addition to being a training site for other healthcare professions including medicine, nutrition, nursing, and physical therapy, Al-Basheer Hospital has established policies and procedures and strong pharmacy input in overall medication management. This allows students to be exposed to these patient populations in a collaborative environment where there are set rules and policies.

Over $80.0 \%$ of students were satisfied with the training site (Al-Basheer Hospital) in terms of resources available for students, orientation conducted in the hospital site, areas designated for group discussions and meetings. The main challenge students encountered was transportation to the practice site.

Future recommendations for the improvement of the programme include expansion to several hospitals either within governmental, private, and/or military hospitals. There is also a need to hire and provide continuous training for preceptors both internal and external. Logistics including transportations and meeting rooms within the training site need to be arranged meticulously to help students focus on the programme, rather than being distracted by minor issues.

\section{Limitations}

Programme implementation limitations: there were difficulties with finding the right hospital for this training, this type of training requires a separate budget that many schools of pharmacy may not have or will need approval to provide. Further development will be needed to collaborate with the Jordanian Pharmaceutical Association to implement legislation for clinical training.

This study didn't have a formal pre/post evaluation of certain knowledge areas although the authors carried out evaluations during and towards the end of this training programme. In addition study changes in learning outcomes in other related courses weren't assessed by the authors. Moreover, due to having a relatively small sample 
size and the fact that not all student filled out questionnaires ( 25 out of 35 ) there is a possibility that the more motivated students were more likely the ones who responded to the post-experience survey.

\section{Conclusion}

ThisThe authors have demonstrated that it is feasible and desirable to train B.Sc. Pharmacy students on skills required to practice pharmaceutical care in a hospitalbased environment. This was however a pilot study to establish a newly designed hospital training programme. Therefore, future larger sample size study need to be done once this training experience expands to the larger number of students enrolled. Students reported positive perceptions regarding the clinical training sites and the staff. They also reported improvement in their clinical and practical skills. This study indicates that this kind of training is successful and can be implemented in other universities.

\section{Acknowledgements}

The authors would like to acknowledge the great efforts of the FPMS dean of pharmacy at UOP, department head of pharmacology and biomedical sciences, dean assistant for international accreditation, and all the students who participated in current study. Also, the authors would like to acknowledge with great appreciation Albasheer Hospital general manager, head of pharmacy department, and medical and pharmacy staff.

\section{Conflict of interest}

The authors declare no conflict of interest in this work.

\section{References}

Ababneh, M., Shamieh, D., Al Demour, S., \& Rababa'h, A. (2019). Evaluation of the clinical pharmacist role in improving clinical outcomes in patients with lower urinary tract symptoms due to benign prostatic hyperplasia. International Journal of Clinical Pharmacy, 41(5), 1373-1378. https://doi.org/10.1007/ s11096-019-00896-2

AbuBlan, R.S., Nazer, L.H., Jaddoua, S.M., \& Treish, I.M. (2019). A Hospital-based Pharmacy Internship Program in Jordan.
American Journal of Pharmaceutical Education, 83(3), 6547. https://doi.org/10.5688/ajpe6547

Accreditation Council For Pharmacy Education Accreditation Standards And Key Elements For The Professional Program In Pharmacy Leading To The Doctor Of Pharmacy Degree. (2015). https://www.acpe-accredit.org/pharmd-program-accreditation

Al-azzam, S.I., Shara, M., Alzoubi, K.H., Almahasneh, F.A., \& Iflaifel, M.H. (2013). Implementation of clinical pharmacy services at a university hospital in Jordan. The International Journal of Pharmacy Practice, 21(5), 337-340. https://doi.org/ 10.1111/ijpp.12009

Al-Wazaify, M., Matowe, L., Albsoul-Younes, A., \& Al-Omran, O.A. (2006). Pharmacy education in Jordan, Saudi Arabia, and Kuwait. American Journal of Pharmaceutical Education, 70(1), 18. https://doi.org/10.5688/aj700118

Alefan, Q., \& Alsmadi, M.M. (2017). Pharmacy education in Jordan: updates. The International Journal of Pharmacy Practice, 25(6), 418-420. https://doi.org/10.1111/ijpp.12344

Anderson, S.L., \& Marrs, J.C. (2018). A Review of the Role of the Pharmacist in Heart Failure Transition of Care. Advances in Therapy, 35(3), 311-323. https://doi.org/10.1007/s12325-018-0671-7

Basheti, I.A., Salhi, Y.B., Basheti, M.M., Hamadi, S.A., \& Al-Qerem, W. (2019). Role of the pharmacist in improving inhaler technique and asthma management in rural areas in Jordan. Clinical Pharmacology : Advances and Applications, 11, 103-116. https:// doi.org/10.2147/CPAA.S213271

Basri, D.S., DiScala, S.L., Brooks, A.T., Vartan, C.M., Silverman, M. A., \& Quellhorst, J. (2018). Analysis of Inpatient Hospice Pharmacist Interventions Within a Veterans Affairs Medical Center. Journal of Pain \& Palliative Care Pharmacotherapy, 32(4), 240-247. https://doi.org/10.1080/15360288.2019.1615025

Benrimoj, S.I., \& Roberts, A.S. (2005). Providing patient care in community pharmacies in Australia. The Annals of Pharmacotherapy, 39(11), 1911-1917. https://doi.org/10.1345/ aph.1g165

Christensen, D.B., \& Farris, K.B. (2006). Pharmaceutical care in community pharmacies: practice and research in the US. The Annals of Pharmacotherapy, 40(7-8), 1400-1406. https:// doi.org/10.1345/aph.1G545

Drugs.com. (2021). Drugs.com / Find Drugs \& Conditions. (online) Available form: https://www.drugs.com

Fang, Y., Yang, S., Zhou, S., Jiang, M., \& Liu, J. (2013). Community pharmacy practice in China: past, present and future. International Journal of Clinical Pharmacy, 35(4), 520-528. https://doi.org/10.1007/s11096-013-9789-5

Hogue, M.D., Grabenstein, J.D., Foster, S.L., \& Rothholz, M.C. (2006). Pharmacist involvement with immunizations: a decade of professional advancement. Journal of the American Pharmacists 
Association : JAPhA, 46(2), 168-182. https://doi.org/ $10.1331 / 154434506776180621$

Kheir, N., Zaidan, M., Younes, H., El Hajj, M., Wilbur, K., \& Jewesson, P.J. (2008). Pharmacy education and practice in 13 Middle Eastern countries. American Journal of Pharmaceutical Education, 72(6), 133. https://doi.org/10.5688/aj7206133

Koga, S., \& Nishimura, T. (2017). Present Activities and Problems of Home Medical Care by Pharmacists. Yakugaku Zasshi : Journal of the Pharmaceutical Society of Japan, 137(8), 941-945. https://doi.org/10.1248/yakushi.17-00001-3

Lexi-Drugs. Lexicomp. Wolters Kluwer Health, Inc. Riverwoods, IL. http://online.lexi.com

Moore, A.F., \& Kenworthy, L. (2017). Disaster Relief: A Look Into the Pharmacist's Role. North Carolina Medical Journal, 78(3), 195-197. https://doi.org/10.18043/ncm.78.3.195

Mukattash, T.L., Bazzi, N.H., Nuseir, K.Q., Jarab, A.S., Abu-Farha, R.K., \& Khdour, M.R. (2018). Pharmaceutical care in community pharmacies in Jordan: a public survey. Pharmacy Practice, 16(2), 1126. https://doi.org/10.18549/PharmPract.2018.02.1126

Nagai, T. (2003). [Pharmacy, pharmacists and society-pharmaceutical science and practice with philosophy]. Yakugaku zasshi : Journal of the Pharmaceutical Society of Japan, 123(3), 143-150. https://doi.org/10.1248/yakushi.123.143

Nazer, L.H., \& Tuffaha, H. (2017). Health Care and Pharmacy Practice in Jordan. The Canadian Journal of Hospital Pharmacy, 70(2), 150-155. https://doi.org/10.4212/cjhp.v70i2.1649

Pittenger, A.L., Chapman, S.A., Frail, C.K., Moon, J.Y., Undeberg, M.R., \& Orzoff, J.H. (2016). Entrustable Professional Activities for Pharmacy Practice. American Journal of Pharmaceutical Education, 80(4), 57. https://doi.org/10.5688/ajpe80457

Saavedra-Mitjans, M., Ferrand, E., Garin, N., \& Bussieres, J.-F. (2018). Role and impact of pharmacists in Spain: a scoping review. International Journal of Clinical Pharmacy, 40(6), 1430-1442. https://doi.org/10.1007/s11096-018-0740-7

Stewart, B., Thomas, R.L., \& Tutag-Lehr, V. (2018). Pharmacists' knowledge, support, and perceived roles associated with providing naloxone in the community. Currents in Pharmacy Teaching \& Learning, 10(8), 10131021. https://doi.org/10.1016/j.cptl.2018.05.016

Supapaan, T., Low, B.Y., Wongpoowarak, P., Moolasarn, S., \& Anderson, C. (2019). A transition from the BPharm to the PharmD degree in five selected countries. Pharmacy Practice, 17(3), 1611. https://doi.org/10.18549/pharmpract.2019.3.1611

Tahaineh, L., Wazaify, M., Alomoush, F., Nasser, S.A., Alrawashdh, N., \& Abraham, I. (2019). Physicians' perceptions, expectations, and experiences of clinical pharmacists in Jordan-2017. International Journal of Clinical Pharmacy, 41(5), 1193-1201. https://doi.org/10.1007/s11096-019-00884-6
Westerlund, L.T., \& Bjork, H.T. (2006). Pharmaceutical care in community pharmacies: practice and research in Sweden. The Annals of Pharmacotherapy, 40(6), 1162-1169. https://doi.org/ 10.1345/aph.1G680

\section{Appendix 1}

\section{Student Testimonials examples}

1: 'During this summer's training session at the Al-Basheer hospital I gained a treasured experience that gave me a new prospective of my field of study. Firstly, I was able to work on and improve my communication skills not only with the patients, but also with the entire medical team, which includes: doctors, nurses and pharmacist. To my surprise, the patients were willing to talk in length about every aspect of their medical condition. I also gained invaluable understanding of how the entire medical team operates together, through observing the interaction between the different medical practitioners. Secondly, I was able to put together all the knowledge and different tools that I have acquired during my years of study at University of Petra in an effort to apply them to a real-life situation. Moreover, this experience gave me exposure to new medical resources that will stay with me forever. Thirdly, participating in medical rounds with Doctors gave me insight into the processes of diagnosis, monitoring and treatment. I had a few discussions with doctors during the rounds, about certain medical cases which further assured me that the knowledge that I have amassed during my years of study was applicable and extremely useful in the hospital setting. In the end, through this training session I was able to achieve such a valuable experience that cannot be replicated in class'.

2: 'Taking this course was probably the best decision I ever made during my school years, it changed my perspective regarding Clinical Pharmacy, as I can practice not only clinical knowledge but also communication skills with patients and medical staff in general, it taught me how to use my basic knowledge in anatomy and physiology and integrate them with pharmaceutical care planning for patients'.

3: 'Before starting the training I was a bit scared of the idea and I thought it was going to be a big responsibility and commitment since we were dealing with serious and real cases for the first time but when I started the training everything was different, everyone was so reassuring and helpful and the team was great. I highly recommend every 
student to be involved in the training because the practice adds a lot to our literature knowledge especially that people tend to have a practical memory and learn a lot by performing rather than reading'.

4: 'I was so lucky to be one of the first students to attend this course, science it taught me how to figure out drug therapy problems and to understand the real role of clinical pharmacist and how he can be part of the medical team'.

5: 'It was Amazing experience since I had opportunities to communicate with patients also, I understand how important the interaction between clinical pharmacist and physicians'. 